Revista de la red interuniversitaria de estudios sobre las literaturas rioplatenses contemporáneas en Francia

$11 \mid 2014$

De niños e infancias

\title{
Pasados, presentes, futuros de la infancia
}

\section{Julio Premat}

\section{OpenEdition}

Journals

\section{Edición electrónica}

URL: http://journals.openedition.org/lirico/1736

DOI: $10.4000 /$ lirico. 1736

ISSN: 2262-8339

Editor

Réseau interuniversitaire d'étude des littératures contemporaines du Río de la Plata

\section{Referencia electrónica}

Julio Premat, «Pasados, presentes, futuros de la infancia », Cuadernos LIRICO [En línea], 11 | 2014

Puesto en línea el 01 diciembre 2014, consultado el 01 mayo 2019. URL : http://

journals.openedition.org/lirico/1736 ; DOI : 10.4000/lirico.1736

Este documento fue generado automáticamente el 1 mayo 2019.

\section{(c) (i) $(9)$}

Cuadernos LIRICO está distribuido bajo una Licencia Creative Commons Atribución-NoComercialSinDerivar 4.0 Internacional. 


\title{
Pasados, presentes, futuros de la infancia
}

\author{
Julio Premat
}

Le génie, c'est retrouver l'enfance à volonté.

Charles Baudelaire.

Buscar las raíces no es más que una forma subterránea de andarse por las ramas. José Bergamín

1 La infancia, espacio conceptual, terreno de creencias, lugar de determinaciones sociales y de ideales compartidos, está recorrida por una atiborrada red de valores culturales, de presupuestos estéticos, de estereotipos y principios ideológicos, de escenas o peripecias con resabios legendarios. Tanto en su imagen mediática, sociológica, icónica o literaria, es un punto de observación privilegiado para identificar modos de explicar el devenir del ser humano. En contrapunto con el mundo adulto, el niño, como el primitivo, permite, gracias a un reflejo alejado o a una otredad significativa, pensar el ahora de la colectividad y avanzar en cierta metafísica del sujeto. Esto es particularmente perceptible en las narraciones de infancia en la literatura, y en una de sus modalidades, la de las autobiografías de escritores, que puede considerarse como un modelo paradigmático al respecto.

2 Varias perspectivas analíticas son posibles : la de evocar, por ejemplo, los postulados que determinan el género biográfico y que han sido profusamente estudiados (postulados que le atribuyen a la vida la forma de un todo orientado, resumido en la expresión unitaria de una intención o de un proyecto; o que considera a la vida como un conjunto que sigue una línea cronológica, percibida como análoga a un orden lógico y que ese orden está organizado a partir de una perspectiva ulterior de carácter teleológico) ${ }^{1}$. También podría verse en la infancia un epítome o un avatar actual de los mitos de origen, a partir de la idea de que, en los relatos de cómo un niño prefigura a un escritor futuro, se actualizaría una versión legendaria de lo genético. Al origen puede vérselo como una proyección de la infancia o, si se quiere, postular que en el origen, ante todo, encontramos a la infancia. La niñez como génesis en la medida en que su relato permite pasar de un hacer (escribir 
literatura) a una forma diferente y socialmente reconocida del ser (una identidad nueva : la de ser autor). Es decir, leer los relatos de infancia de escritores desde la perspectiva de una explicación mítica del inicio -una explicación hecha de una serie de acontecimientos que se suceden, a la vez enigmáticos y fundadores-, lo que sería una modalidad de supervivencia de esquemas narrativos tradicionales (para dar un ejemplo: como el Génesis y el Apocalipsis, el comienzo y el fin, que Franz Kermode estudia en El sentido de un final, 2000). O, por último, poner de relieve todo lo que, en las concepciones culturales y los atributos imaginarios de la infancia la asocian, en sí, con el discurso literario: espacio aparte, relación diferente con la palabra, mezcla inextricable de subjetividad y de percepción, posibilidad de percibir la realidad de manera alternativa, expansión del deseo y de la imaginación en tanto que supuestas verdades, etc. El pensamiento singular de los niños, visto por dispositivos de todo tipo, es un modo de aproximarse a las especificidades de la palabra literaria.

Combinando estas tres perspectivas, pero privilegiando la visión del relato de infancia como laboratorio literario, me dispongo a desarrollar algunas ideas generales, en tanto que preámbulo a la evocación de ejemplos que, a partir de la puesta en escena autobiográfica del inicio de la vida de un escritor, esbocen una modesta tipología.

\section{Infancias escritas, orígenes literarios}

4 Para comenzar, vale la pena recordar que los niños no escriben, los niños no definen su mundo ; la infancia es una creación de adultos que ven, en esa etapa diferente de la vida humana, una otredad a la vez radical y familiar, una manera de explicar al sujeto. Como todo origen, la infancia está vista desde el después, es una construcción y funciona como un horizonte de sentidos cifrados pero determinantes. Mundo de utopía, esfera del inicio, promesa del futuro, la infancia es un pasado visto en el presente que permite soñar un porvenir distinto. Y lo que a biografías se refiere, notemos que el niño es una ficción del adulto que pretende que su infancia está acabada, una ficción, a menudo estereotipada, que perdura imaginariamente en cada uno de nosotros, tanto del lado de lo pulsional y lo conflictivo como en la ensoñación y la creencia.

5 Esta escritura posterior, tan evocadora, no es arbitraria sino que retoma huellas y resabios de una experiencia del mundo vivida en la niñez. Al respecto, Jean Piaget intenta comprender cómo los niños se representan lo real y cómo explican lo que los rodea, modalidades que no son ajenas, claro está, a la puesta en escena de universos y puntos de vista infantiles en la literatura. Ante todo, cabe evocar el carácter autocentrado, egocéntrico del niño, que lo lleva a borrar la frontera entre lo interno y lo externo o, mejor dicho, a introducir al yo en los juicios, ilusiones, percepciones, que son por lo tanto subjetivos -la objetividad, para existir, impone tomar en cuenta la posición del sujeto-. Por lo tanto, el niño sería realista, en el sentido en que ignora la existencia del yo al adherir a su propia perspectiva como si fuese inmediatamente objetiva y absoluta, pasando por alto la interioridad del pensamiento desde una posición antropocéntrica. Se entiende entonces que los niños proyecten, a causa de la indiferenciación entre el sujeto y el mundo exterior, las características del yo, sus estados de ánimo o sus ideas, a lo que los rodea -inclusive en la eventualidad de objetos o seres que tendrían, gracias a esa proyección, intenciones amenazadoras-. Este egocentrismo es a la vez lógico y ontológico : el niño fabrica su verdad y su realidad. No conoce la resistencia de las cosas ni la dificultad de las demostraciones. Puede afirmar sin pruebas y dar órdenes sin 
limitaciones. Los lazos lógicos están así marcados por esta constatación; se confunden causas psicológicas y físicas; las representaciones de la realidad, de las palabras y de los sueños tienden a superponerse y a mezclarse (Piaget, 1999 : 141-142).

6 En una orientación similar a Piaget, pero más cerca de lo artístico, Giorgio Agamben, en Infancia e historia, postula que el niño pertenecería, a su manera, a la naturaleza y no a la cultura. Pensar como un niño es pensar antes, antes la edad de la razón. La infancia es el lugar que precede el lenguaje y el conocimiento, instrumentalizando una mirada diferente sobre la realidad, es decir, otro conocimiento y, en consecuencia, otro lenguaje. Es, por lo tanto, el lugar privilegiado para la iniciación del escritor en su versión legendaria. Agamben agrega que la infancia, como la literatura o el juego, tiende a rechazar la escisión entre tiempo cronológico y tiempo estático (entre tiempo del mundo y tiempo del sujeto, tiempo biológico y tiempo subjetivo), reintegrando, en las vivencias y en la experiencia, esta doble cara del tiempo. De allí la importancia, por ejemplo, de los relatos de infancia en lo fantástico o en lo maravilloso, relatos que intentan recuperar representaciones del mundo y funcionamientos lógicos de la niñez. De allí, también, el valor de la creencia y el valor interpretativo atribuido a la literatura, en tanto que universo en alguna medida afín al pensamiento infantil (Agamben, 1989:128). El niño es un receptáculo de proyecciones sociales, culturales, ideológicas, gracias a las cuales se intenta comprender y justificar el mundo de los adultos, desde otro lugar, lo que lo pone en relación con la utilización del arte y de la imaginación como instrumentos de conocimiento.

7 Prolongando esta idea, recordemos que Marthe Robert da como origen de todas las narraciones una expansión de fabulaciones infantiles. Partiendo de la novela familiar definida por Freud y la construcción de fantasías genealógicas que compensan los deseos frustrados y las ineludibles prohibiciones, ella identifica en la producción narrativa dos tipos de visiones primitivas: la del niño hallado, capaz de transmitir como verdaderos todos los sueños y quimeras en una visión maravillosa del mundo (es decir el que intenta mantener vigente ese «mundo hiperbólico de la primera infancia » que, aunque tiene tendencia a perpetuarse, se enfrenta con la evolución del individuo), y la del bastardo realista, que negocia con los imperativos de la realidad para lograr una proyección fantasmática a la vez velada y eficaz bajo la apariencia de lo verosímil (lo que se resumiría en la dialéctica de " el 'sí' al mundo y el 'no' a la realidad ») . Cervantes o Swift, formarían parte de la primera categoría junto con, por ejemplo, García Márquez o Felisberto Hernández (Robert, 1972 : 45 y 233).

8 Ante la desaparición social de las narraciones de lo experimentado que postulaba Benjamin (1991: 263-291), la infancia sería legendariamente el tiempo de lo vivido también en la expresiones espontáneas del deseo-, en contrapunto al tiempo del pensamiento. Así retorna, desde el sesgo, una potencialidad perdida de la imaginación, que era otrora un vector de conocimiento : la imaginación (algo soñado, una visión) fue alguna vez considerado equivalente de la experiencia. En ese sentido Agamben considera que la infancia sería el tiempo de la experiencia por definición, ya que la única posible hoy es la que se lleva a cabo antes de la constitución del sujeto por el lenguaje. Esto explicaría que la infancia sea un espacio de proyecciones míticas y legendarias alrededor de otra relación posible con el mundo y por ende de otras posibilidades narrativas. Más allá del sujeto racional encontramos al niño, cuyas representaciones no estarían alejadas del inconsciente freudiano o del flujo de consciencia en la literatura (Agamben, $54 \mathrm{y}$ 83-85). La infancia vista en tanto que otredad y espejo, espejo de lo otro en donde uno se 
reconoce sabiendo que no es uno: un sujeto que hay que inventar para que sea verdad, todo lo cual no es ajeno a los cimientos de la ficción.

La infancia, mundo conocido que permite todas las novedades, ámbito de reglas establecidas que se puede transgredir, la infancia, en tanto que mundo específico de creencias, imaginario y explicaciones alternativas de lo existente, la infancia, en donde no sólo se puede tematizar la creación, sino exponer los mecanismos elementales de la ficción : la mentira, la imitación, la fabulación deseante, el ensueño, el juego, la lectura. La infancia sería, entonces, el equivalente de la literatura.

Pero si la literatura es la infancia, la equivalencia eventual no se reduce a lo que podemos calificar de una metafísica de la niñez, sino que también ha sido leída como un laboratorio de escritura, es decir como un espacio de definición de estilos, códigos de representación, invención de formas. Es sabido que en las autobiografías los episodios infantiles exigen menos verosimilitud y veracidad que los otros episodios: el relato imaginario y la improbabilidad de los recuerdos convocados (a menudo inventados, soñados, dudosos) forma parte del género y de su pacto de lectura. Se transcribe una percepción peculiar y un sujeto prelógico, más que una verdad histórica (y de todos modos estos episodios están marcados por afirmaciones sobre la dificultad del recuerdo y la incertidumbre que caracteriza lo que será narrado). Por lo tanto, y teniendo en cuenta esta dificultad de juzgar la fidelidad de lo evocado, Philippe Lejeune constata que, con contadas excepciones, los relatos autobiográficos de infancia no han entrado en la« era del recelo » que caracteriza al resto de las biografías. Una de las razones es que los recuerdos de los que se trata, aunque discontinuos e inciertos, son a menudo intensos, y la intensidad parece asegurarles una veracidad. Así, el régimen habitual del recuerdo de infancia es el lirismo y su territorio es el de la fe. Por definición es difícil acceder a las vivencias infantiles; de hecho, esa búsqueda iniciática y titubeante aumenta el valor de lo que se recupera, como lo que descubre un arqueólogo en capas superpuestas y enterradas de una civilización desconocida (Lejeune, 2003 : 36). Ampliando la perspectiva, es concebible establecer una analogía con el concepto freudiano de construcción de una interpretación o la fabricación un recuerdo (por ejemplo, los recuerdos encubridores), construcción cuya veracidad es más funcional que documental : la ficción sobre un pasado remoto puede ser cierta cuando lo que se rememora está, para siempre, fuera de alcance, como lo está el origen del monoteísmo (en El hombre Moisés y la religión monoteísta) o las escenas primeras de la vida de un hombre (Green, 2000 : 43-45 y Brauer, 2010).

11 Esta posición diferente ante los imperativos de la verdad, la verosimilitud y la lógica explica que la infancia sea un terreno experimental, idóneo para retomar la fenomenología de la sensación, la inocencia descriptiva y una reconfiguración de la creación estética. La crisis de la capacidad expresiva de la novela en el siglo XX lleva a refugiarse en la infancia, escapándose de la representación naturalista de inspiración científica para continuar refiriéndose a la realidad a través de lo irracional y de una relación distinta con el lenguaje, como lo postula Alexandre Gefen (265-273), afirmaciones que retomo en lo que sigue. La escritura de la infancia es inseparable del desarrollo de las restricciones de focalización (como la practicada por Henry James), la polifonía, el solipsismo (Proust) y ante todo el monólogo interior que confunde lo externo y lo interno, la materia y el pensamiento, el flujo de sensaciones, las construcciones abstractas de la afabulación y el movimiento proyectivo de la imaginación temporal (piénsese en la primera parte de El sonido y la furia de Faulkner o en "Macario" de Rulfo). La escritura de la infancia permite también desplazar los límites del lenguaje, instituyendo un relato 
poético sobre mundos autónomos que pone lo real de lado y funciona alrededor de metáforas objetivadas y de asociaciones totémicas. Por último, el carácter originario, explicativo y fundador de la infancia, representa la génesis de la consciencia y al mismo tiempo la génesis del mundo, metaforizando a la creación, a sus posibilidades y sus dificultades. Reescribir el origen es reinventar la forma novelesca, aunque más no sea en el gesto de atribuir a ese otro inalcanzable que es el niño la dificultad de acceder a la comprensión del mundo. Dificultad de comprensión para el sujeto en vías de formación que metaforiza una dificultad inherente, como es sabido, a la novela moderna.

Desde la perspectiva del origen mítico, en donde una creación ex nihilo del mundo y un momento perdido explicarían, mágicamente la emergencia de la obra literaria; desde la idea de la construcción posterior que a la vez actualiza y simboliza la pérdida y el deseo de recuperación ; desde la esfera de la creencia, de la permanencia de una utopía de otras posibilidades, de la experiencia prelógica y prediscursiva ; o desde la constatación que se trata de un terreno idóneo para definir una aprehensión específica el lenguaje, el saber, la narración, el imaginario, desde todos estos puntos de vista la infancia ocupa entonces un papel central en las construcciones autobiográficas de los escritores. 0 , mejor que un papel central, digamos que ocupa un lugar aparte : por un lado, los orígenes y la primera infancia son un relato en sí mismo, regido por sus reglas de verosimilitud, un tipo de relación específico con el mundo y con el aprendizaje, una dinámica explicativa que obedece a reglas propias, todo lo cual se diferencia a menudo del pacto referencial y la lógica narrativa que caracterizan, luego, los relatos de la juventud y de las diferentes peripecias de una vida adulta.

\section{Testamentos}

Para estudiar cualquier relato autobiográfico, si constatamos que se escribe desde un presente y en respuesta a solicitaciones de un entorno preciso, es indispensable plantearse la pregunta del cuándo de esa escritura. En esta perspectiva, y la historia de la literatura lo muestra rápidamente, dos posibilidades se presentan, dos posibilidades que, como toda clasificación dicotómica, simplifican en exceso la multiplicidad de eventualidades ; simplemente, al subrayar dos casos extremos, se vuelve más visible un funcionamiento que, con todos los matices peculiares, sería perceptible en el conjunto de rememoraciones de este tipo. Por un lado, la narración desde el final de una trayectoria : en la vejez, en vísperas de la muerte, en un esfuerzo postrero de escritura. Aquí los relatos del comienzo son una última palabra, o un testamento. Un testamento entendido como una carta del pasado al futuro que, para decirlo con Hannah Arendt, selecciona y nombra, transmite, preserva e indica dónde están los tesoros y cuál es su valor, todo lo que constituye la función principal de la tradición (selección, transmisión, jerarquización, orientación para la recepción) (Arent, 1995 : 75). De una tradición en la que el escritor espera inscribirse, también y ante todo con la escritura de sus "memorias", con la actualización de su figura gracias al retorno al mito de origen que delimita una intención y explica de manera orientada un proyecto. Por el otro, un regreso a la infancia y a los comienzos, puede funcionar, al contrario, como la apertura de una obra literaria, un gesto para entrar en el campo, un ejercicio para lanzar las especificidades de una palabra que se quiere singular. Obras de juventud $u$ obras tempranas, se trata de relatos que no se proyectan hacia el futuro en tanto que legado restringente, sino en tanto que fundaciones 
de una obra por venir. Para completar el panorama general, algunos comentarios y ejemplos sobre estas dos eventualidades.

De lado del testamento y de la escritura en el umbral de la muerte, los ejemplos de Pablo Neruda (que dicta Confieso que he vivido a su secretario y no llega publicar el libro en vida) o Reinaldo Arenas (que termina Antes que anochezca como punto final de la escritura de su obra, antes de suicidarse -el final del libro es una declaración política que intenta darle un sentido anticastrista a su enfermedad y muerte-), son, a pesar de las abismales diferencias entre los dos libros, paradigmáticos. Sin tener la dimensión fuerte de un libro del final de una existencia, Volver para contarla de García Márquez obedece a una lógica similar, en el sentido de que se trata de volver sobre lo escrito, desde la vejez y después de una grave enfermedad (Márquez, 2009) para instaurar -en buena medida repetir- un tipo de lectura y un sistema interpretativo de una obra cuyo éxito excepcional resulta enigmático para el escritor y exige, por lo tanto, un relato explicativo. Sin entrar en el análisis detallado de estos tres libros muy conocidos, enumeremos algunas características comunes que remiten, en varios aspectos, a lo dicho más arriba.

Por lo pronto, los tres textos determinan un espacio singular para la infancia, diferente de la vida urbana posterior : el Temuco de un sur de Chile idealizado, hecho de presencias indígenas, bosques antediluvianos, flora y faunas extraordinarias expandiéndose entre volcanes y océanos, en el caso de Neruda. El campo del Oriente cubano para Arenas, en una casa primordial rodeada por una vegetación tan exuberante como lo son las expresiones multiformes y obsesivas de una sexualidad omnipresente, un espacio en que lo humano y lo animal se combinan y donde proliferan los cuerpos desnudos y las erecciones descomunales : un Belén amenazante, tropical y erotizado, podría decirse. La célebre Aracataca de García Márquez, a la que el escritor, de veinticinco años, vuelve en el relato que abre su autobiografía, afirmando explícitamente que ese viaje le permite descubrir que sus recuerdos del pueblo, sin relieve, eran falsos, reemplazándolos entonces por otro pueblo y otros recuerdos, fruto de la imaginación y la nostalgia, recuerdos de infancia llenos de misterios, excesos, relatos seductores y cataclismos ${ }^{2}$ Aracataca se vuelve una Arcadia literaria y una cifra del universo-. Es un espacio aparte, perdido : Neruda viaja a Santiago al final del primer capítulo de su libro, Arenas deja el campo por Holguín y por una vida morosa en donde el aprendizaje pasa ahora por la escuela, el cine y las lecturas, García Márquez se focaliza para siempre en el abandono de Aracataca después de la desaparición de la casa y de los abuelos, lo que convierte a ese pasado en un lugar imaginario al que se retorna a la hora de narrar.

16 La otredad espacial, que no es sólo geográfica sino ontológica (la casa fabulosa y la naturaleza desmedida son los cimientos de representación de una realidad intrínsecamente diferente a los de cualquier recuerdo verosímil), se prolonga, claro está, en una representación de un tiempo fuera del tiempo : tiempo del Génesis en Neruda y de los ciclos naturales, del diálogo con los árboles y con las leyendas en Arenas, de los cataclismos, las fábulas y la transgresión de fronteras entre la verdad y el imaginario en García Márquez. Son tiempos premodernos, radicalmente distintos, en los cuales lo primigenio no significa una anterioridad histórica sino un primitivismo intemporal. En los tres se expanden las coincidencias maravillosas, lo sobrenatural, lo imposible, en tanto que característica esencial y opuesta al tiempo adulto de la historia cronológica: la infancia se aleja hasta confundirse con el tiempo de lo arcaico, de lo legendario, del comienzo fabuloso de todas las cosas. Y los tres dramatizan la ruptura vivida como el abandono de ese espacio-tiempo, a la vez mítico e inherente a tantas construcciones de la 
literatura latinoamericana. El paso de la infancia al realismo de la edad adulta se metaforiza por el consabido paso del mundo agrario a la modernidad urbana.

En ese cronotopo particular las experiencias tienden a narrar, si no a volver inteligible, los rasgos fuertes una figura de autor. Un autor que no se define entonces como el resultado de un proceso, de un aprendizaje, de encuentros, lecturas y peripecias, sino que tiene una identidad en alguna medida innata, absoluta, que sólo espera revelarse : no sin cierta monstruosidad, estos niños precoces son, ya, diminutos escritores. En consonancia con el medio geográfico y también, muy particularmente, con el entorno familiar entramado de ecos para construir una imagen peculiar-, asistimos a una serie de manifestaciones que prefiguran la obra posterior, definiendo los rasgos mayores que ésta tendrá, todo lo cual actualiza el mito de un origen en tanto que condensado anunciador del futuro y que determinante absoluto. Neruda escribe su primer poema de amor a una mujer (la esposa del padre) después de la muerte de un cisne en sus brazos y de un episodio de observación solitaria y fascinada de la naturaleza gigantesca del sur chileno (30-31). Arenas, antes de saber leer y escribir, realiza representaciones teatrales solitarias de marcada energía, en las que mezcla música, letra y actuaciones delirantes, gesticulaciones agudas y chillidos ininteligibles, todo lo cual parece condensar la marginalidad imaginativa y el histrionismo deseante de su prosa (37). García Márquez, que de niño tenía "recuerdos intrauterinos y sueños premonitorios" (81), es ya entonces un narrador que fabula, miente y deforma las historias que le narra a los adultos, agregando siempre una dosis imaginativa anómala, gesto rudimentario de un narrador en ciernes que busca hacer la realidad "más divertida y comprensible" (104).

Los tres, con objetivos distintos pero de manera simétrica, citan e incluso reescriben en estos episodios sus obras literarias, obras que están, en ese entonces, terminadas; una reescritura ambigua, ya que los episodios ficcionales o las evocaciones poéticas vuelven, se repiten, pero teñidas de contenidos biográficos $\mathrm{y}$, en contrapunto, la reminiscencia de la infancia se hace desde los materiales narrativos o poéticos ya escritos y divulgados. Sea como fuere, el regreso imaginario a la infancia y el regreso a la obra van de par y establecen, en los tres casos, un legado digamos semántico : una orientación de lectura que pasa por una explicación legendaria y por la actualización de una figura de autor.

¿Con qué sentidos? El texto de Neruda es a menudo una involuntaria autoparodia que propone una visión reductora de su trayectoria poética. Recorre una serie de tópicos temáticos, tanto sobre la materialidad, el arcaísmo mítico de América como sobre tomas de posición ideológicas (masacres de indios, genealogía de trabajadores, exaltación de los obreros y de la gente "simple"). De hecho, el primer capítulo de Confieso que he vivido suena como un epitafio o un homenaje a sí mismo : el último rasgo de la estatua de poeta hugoniano que él se construye de cara a la posteridad. Más allá, subrayemos la insistencia con la que se retoman esquemas estereotipados de la autobiografía de infancia; el relato construye a un personaje acorde con la obra posterior, en una estrategia de selección y de actualización de elementos dispares, incluso contradictorios, pero necesarios para dar una imagen completa, enteramente determinada en estos primeros años. $O$ sea, preexistencia mítica de la escritura en el niño (no hay un "volverse" poeta, un devenir, sino una afirmación ab aeterno de su identidad) ; relación peculiar con un espacio hecho de elementos primordiales y de colectividades arcaicas, alejado en el tiempo y opuesto a los espacios de actividad literaria; personalidad aparte marcada por una sensibilidad extremada y por una imaginación diferente, construcción de una filiación personal que desborda la historia familiar (hijo de nadie, hijo de la tierra, hijo de todos); visión acorde 
con una estética rígida y una concepción social. $\mathrm{Y}$, a cada paso, se repiten las temáticas y las intenciones de la obra futura (o sea, pasada). Hay abundantes paralelismos, por ejemplo, con la sección "Yo soy" del Canto general y en particular con el primer poema "La frontera (1904)" (Neruda, 1983 : 449-480). Se trata de una fábula, telúrica, lírica y mítica, de inserción en la historia de las letras a partir de una personalidad diferente, todo lo cual antecede, supuestamente, la entrada del joven Pablo Neruda, a los veinte años, en el mundo literario de Santiago.

En los episodios de infancia de Arenas encontramos, otra vez, una prefiguración legendaria del Arenas adulto, biográficamente en lo que atañe a la sexualidad y también a la dimensión de autoanálisis postrero que posee el texto (el origen personal, el personaje de la madre, el entorno familiar, son una y otra vez interrogados). Pero, ante todo, una prefiguración del escritor. La infancia es el momento literario por excelencia : en esta esfera primitiva, misteriosa y profusa emergen los valores estéticos que podrían resumir una poética de Arenas autor: imaginación, libertad, sensualismo, exuberancia, magia, rechazo de la censura o escritura a partir y sobre la censura, múltiples distorsiones e invenciones sobre grupos familiares. Su filiación imaginaria también participa en la definición de una figura y por ende en el sentido de una obra : a la vez femenina, anti jerárquica, y sobre todo anti intelectual, natural, espontánea, con la fuerza de la rebelión y del deseo, en donde el barroquismo desenfrenado adquiere, entonces, una justificación gracias a ese mundo inverosímil pero coherente. Sin embargo, al volver a numerosos episodios presentes en su obra (tanto en Celestino antes del alba, su primera novela, como en muchas otras) insertándolos en un marco autobiográfico y al establecer una analogía entre la vida y la obra, Arenas retoma a su manera una tradición literaria reconocible : el texto es más transgresivo en las representaciones de la sexualidad infantil, por ejemplo, que en sus postulados causales y narrativos. También intenta orientar la recepción futura de su obra a partir de los valores anticastristas y las reivindicaciones de la libertad sexual (libertad que se superpone de manera inextricable con la escritura en sí), es decir que por un lado explica pero por el otro busca fijar sentidos de lo ya escrito, interpretando el conjunto a partir del final inminente de su vida.

21 Vivir para contarla amplifica, en alguna medida, declaraciones recurrentes de García Márquez sobre su obra y en particular sobre Cien años de soledad, en la medida en que allí se busca probar la dimensión autobiográfica, o digamos referencial, de esa novela y de buena parte del resto de su producción : una serie muy abundante de anécdotas, frases y personajes de la ficción aparecen en este relato que, según el pacto genérico, debería ser "sincero" y "realista". También retoma la creencia en lo narrado, la posibilidad de evocar con la fuerza de la nostalgia un tiempo perdido al que se adhiere, la naturalidad del cruce entre verosimilitud y magia. De cara a una carrera de escritor, y al final de su vida, García Márquez reanuda, una última vez y gracias a un nuevo relato de infancia, el gesto de apropiación de un pasado que no fue, que pudo haber sido, que se sueña como real. Es decir que al actualizar en su autobiografía la vivencia infantil de pérdida, de creencia, de magia, muestra, hasta el final, que no renuncia a evocar y volver verosímil ese mundo fantasmático, repitiendo que lo perdido tuvo cierto tipo de existencia.

En los tres, pero ante todo en García Márquez, la infancia aparece como un muestrario estético e imaginario construido retrospectivamente. Porque en el relato del regreso a Aracataca y sus derivaciones encontramos no sólo un repertorio temático, una novela familiar, una prefiguración de una identidad de escritor, sino que el episodio, tan diferente del resto del libro, también muestra una modalidad, una estructura, un tono, 
una perspectiva sobre lo narrado, un tipo de relación con la realidad; vale decir, lo que sería una ars narrativa ; el episodio inaugural de la autobiografía narra el origen e ilustra, en su textualidad misma, el resultado de ese origen, es decir una poética, un estilo, una relación con el mundo. La escritura, aquí, está dos veces condicionada por su origen : en tanto que causa legendaria y que práctica concreta. Este aspecto es particularmente visible porque, después de los episodios infantiles, el resto del libro está redactado en un tono de autor cronista (y afirmaciones semejantes podrían hacerse sobre Neruda y Arenas). En cambio, el inicio, los episodios de la infancia, son una prolongación anacrónica de la obra de ficción : la causa viene después del efecto y el muestrario de una escritura vale tanto como la verdad imaginaria de lo que se está narrando.

\section{Fundaciones}

Bien diferente es el caso de los autores que recurren a la infancia, y más específicamente a la propia infancia, en el período en que comienzan un proyecto literario o al menos en el momento de recomponer las coordenadas de un proyecto narrativo. La retrogradación al universo infantil, los intentos de focalizar la mirada del mundo a partir de una percepción anómala y primaria, la búsqueda de hallazgos discursivos, las concepciones alternativas de lo real, todo lo que corresponde a estas escrituras de la niñez, son una especie de regresión al universo que nutre la imaginación y el lenguaje, un interrogante a los fundamentos supuestos de la ficción, una construcción de figura de creador a partir de la actualización -la invención- de un yo niño, capaz de tomar la palabra y delimitar las características de un estilo. En este sentido, la infancia no tiene la función explicativa de lo ya escrito sino, al contrario, la de retomar el origen y sus valores simbólicos para empezar, para empezar de nuevo más precisamente, y fundar entonces una obra literaria aparte, reconocible entre las demás como un corpus singular. 0 , al menos, para retomar una voluntad de obra por escribirse a partir de la revisión de fundamentos estéticos y lógicos. En estos casos no sólo no se "vuelve" a la infancia en tanto que pasado remoto sino que se intenta alcanzar una niñez que, de algún modo, sigue estando y puede reactivarse.

Significativamente, los ejemplos que voy a comentar son los de dos vanguardistas (o neovanguardistas, o vanguardistas periféricos), Felisberto Hernández y Norah Lange, y el de un escritor transgresivo, rupturista, provocador, Fernando Vallejo. El de un Felisberto que, como la crítica lo ha repetidamente indicado, publica una serie de libros a la vez breves y radicales en los años treinta (Fulano de tal, 1925, Cuaderno sin tapas, 1929, La cara de Ana, 1930, entre otros), y que, a fines de los cuarenta, escribe algunos de los cuentos más originales y logrados de la lengua castellana (los agrupados en Las hortensias y Nadie encendía las lámparas). Entre esas dos etapas, se inscribe otra, la del "memorialista", fundamentalmente concentrado en los recuerdos de infancia más o menos autobiográficos (ante todo en Por los tiempos de Clemente Colling, 1942 y El caballo perdido, 1943)3. Aunque el cambio y la disociación que a menudo se establecen entre el primer y el tercer período puedan discutirse (Laura Corona Martínez lo hace con pertinencia) ${ }^{4}$, es evidente que en el escritor se produce una especie de introspección, de concentración en sí mismo, de interrogante a la lengua, a la percepción y al mecanismo creativo, que pasa por la infancia y que da como resultado sus mejores libros. No necesariamente una ruptura radical con lo anterior, pero sí, en el universo de posibles que esos textos tempranos ofrecían, la elección de un tipo de mirada y de sintaxis gracias a ese retorno 
imaginario a la propia infancia. Y, como la crítica lo ha señalado repetidas veces, los cuentos principales de Felisberto se caracterizan por un tipo de percepción y una representación del sujeto, de inspiración infantil, que cobran su forma visible, se definen como factibles y como programa, en los libros de inspiración autobiográfica.

Por su lado, Norah Lange, presente de manera periférica en los grandes momentos de la vanguardia rioplatense, escribe, un poco a la sombra del inmenso poeta que fue su marido, Oliverio Girondo, tres libros de poemas y dos novelas que no logran definir una voz singular ni una vía creativa fértil (a pesar del éxito del humorismo un poco escandaloso del relato de viaje novelado 45 días y 30 marineros, 1933). El cambio se produce con su texto más conocido, Cuadernos de infancia (1937) en donde ciertos mecanismos de dislocación perceptiva y de fragmentación son asociados a una revisión singular del mundo infantil. A partir de este libro, los siguientes, sin lograr una visibilidad importante en el campo literario, prolongan los hallazgos y los tonos de ese primer libro autobiográfico, a veces radicalizándolos (por ejemplo Antes que mueran, 1944 y Personas en la sala, 1950) $)^{5}$. Lange encuentra su tono y su proyecto, aunque ciertas condiciones específicas de su figura y del campo literario argentino no le hayan atribuido, hasta ahora, el lugar preeminente que merece.

Fernando Vallejo, como es sabido, fue primero biólogo y luego cineasta. Tardíamente se acerca a la producción literaria, primero con una gramática de la creación literaria (Logoi. Una gramática del lenguaje literario, 1983 : extraordinaria anécdota de un comienzo de escritura a partir de una determinación de las reglas que el propio escritor va a aplicar y a transgredir), y luego, cuando tiene ya 43 años, comienza su carrera de escritor con un ciclo autobiográfico, cuyo primer libro, Los días azules, se publica en 1985. Esta evocación de la infancia será fundadora en varios sentidos: por lo pronto, porque establece una mirada, característica en toda la obra, de nostalgia y rechazo por los cambios sucedidos en Medellín y en Colombia después de esa infancia. Por otra parte, el tipo de narrador, que se sitúa entre la autobiografía y la autoficción, se prolonga en los libros posteriores, sean éstos autobiográficos (como todo el ciclo de El río del tiempo, del cual Los días azules es la primera parte, o El desbarrancadero) o no lo sean (como su novela más conocida, La virgen de los sicarios y algunos volúmenes de biografías, ensayos y panfletos). Por último, como veremos, ese libro sobre la infancia establece un tono y una serie de marcas estilísticas, que son no sólo inherentes a toda su producción, sino que aparecen como el rasgo identificatorio del escritor, su singularidad más visible.

Desde lugares muy distintos, los tres radicalizan un tono narrativo. Felisberto y Lange, en particular, llevan hasta sus últimas consecuencias la reconstrucción de una tonalidad infantil y una percepción consecuente de lo real, lo más alejadas posible de la distancia del adulto hacia el niño, distancia a menudo reconocible en estos relatos. Ambos intentan transmitir una mirada alógica, en la que domina la percepción sin preconceptos previos, es decir una percepción que intenta adherir a la experiencia que se produce sólo en la infancia, según las afirmaciones de Agamben citadas. Sin el halo de la excepcionalidad ni la inclusión de recursos a lo maravilloso o a lo mágico, el mundo interior y el mundo exterior tienden a confundirse, en un leve animismo de gran verosimilitud. Analogías sorprendentes, personificación de los objetos, acumulación de impresiones inconexas, sensaciones transmitidas sin un entorno explicativo, son algunos de los recursos narrativos que, en Felisberto sobre todo, definen una visión literaria de lo real. Pero a diferencia de García Márquez, la visión autobiográfica no llega en este caso después, como explicación de la dimensión mágica que caracterizaría sus literaturas ; aquí asistimos a la 
emergencia en sí de esa dimensión (y por eso mismo, ésta está mucho menos marcada por presupuestos culturales como lo real maravilloso y por la intertextualidad con los mitos de origen, o sea por esos supuestos relatos de una "infancia" de la humanidad).

En ambos, la posición no es la de la determinación en la infancia sino la del interrogante sobre ella, como si toda operación de escritura consistiera en transmitir algo inasible, extraordinario, y por lo tanto literariamente excepcional. Estamos, sí, en la infancia como mundo aparte y como universo de sensaciones, percepciones y deseos específicos, pero no en la determinación ni en la atribución de sentido, sino en su opuesto : es la mirada lo que domina, una mirada que se topa con la extrañeza o, mejor y en una clara tradición vanguardista, el extrañamiento (el ostranenie). La Mirada excéntrica, una mirada que no es candorosa sino que integra crueldad, miedos y pasiones, la reinvención de una realidad constantemente descubierta, la innovación de una perspectiva radicalmente diferente, el abandono de la explicación en beneficio de la representación singular, el privilegio dado a la imagen visual hermética o a la analogía inesperada, la fluidez de una fragmentación estructurante, principios asociables a tantos -ismos de los veinte y los treinta, todo esto encuentra en la niñez un terreno privilegiado de expresión. Es decir que el cronotopo de la infancia, aunque sea tan excepcional aquí como en los ejemplos precedentes, no tiene el halo de lo legendario y lo irremediablemente perdido, sino que es una metaforización prolongada de la literatura, de sus posibilidades, de sus enigmas ante un universo incomprensible.

Por supuesto, en un contexto histórico y literario muy diferente, las operaciones que lleva a cabo Vallejo no son comparables en sus contenidos aunque sí, quizás, en los postulados funcionales que las caracterizan. Me detengo, para terminar, un poco más extensamente en este ejemplo.

En el extraordinario comienzo Los ríos azules (1985) se define primero una puesta en escena de la enunciación (el narrador se dirige a alguien, con una oralidad tumultuosa, digresiva y sofisticada al mismo tiempo), así como se narra una serie de recuerdos disparadores y estructuradores de la escritura. Menciono tres, de las primeras páginas del libro. Primero, la rabieta del niño Fernando, al que una« criadita infame" priva de chocolate cuando se ausenta la madre. La doble ausencia no da lugar a un juego de simbolización de la privación (un fort-da freudiano, digamos) sino a una furia que se manifiesta en la imagen del niño golpeándose la cabeza contra el embaldosado del patio ( ¡Bum! ¡Bum! ¡Bum!» son las tres primeras palabras del texto), en una excitación dinámica que se convierte en un verdadero torrente de escritura. Cito unas líneas del segundo párrafo :

La frente del niño rebotaba contra la baldosa del piso en un redoble in crescendo rítmico, furibundo, y los tornillos, las tuercas, las ruedas, las roscas, los clavos, los muelles, los ejes, las cuñas, las hélices, el cigüeñal, el torniquete, el embrague, las coordenadas, las abscisas, los planos, las líneas, las simetrías, el sutil engranaje todo de mi cabeza se iba aflojando, desajustando, borrando, hasta que la pobre se convertía en una calabaza hueca que seguía dando tumbos, ciegos, sordos, por inercia de la furia, contra la terca inmensidad del mundo (25).

La furia contra la dureza y la risa burlona de la criada pronto se convierten en furia contra la «terca inmensidad del mundo", y dan lugar, como puede juzgarse, a una avalancha discursiva: la onomatopeya, la acumulación, el desajuste sufriente, la interlocución furibunda, definen una posición de escritura y una irresistible fuerza léxica. 

la que se producen estas escenas de rabia. El« arroyo manso, terso, cristalino, » que pasa frente a la casa de la infancia, la quebrada Santa Elena, todos los años se desborda tumultuosamente, hasta transformarse en torrente y en avalancha, por lo cual la quebrada cambia de nombre para ser llamada quebrada La Loca :« Rugiendo, despeinada, La Loca se lanzaba sobre Medellín amenazante " recuerda el narrador. Y ante todo se lanza contra la casa familiar, desbaratando el orden y obligando a inversiones múltiples (en particular, a sacar afuera lo que estaba adentro, es decir los muebles y las marcas de una intimidad y, a pesar de los intentos de arreglo, a constatar la ruina de las cosas, por ejemplo del piano, que a partir de entonces« quedó sirviendo para lo que sirven las tetas de los hombres ", es decir aparentemente para nada, salvo para decorar) (30).

ultimo, tercer recuerdo inmediatamente posterior, el del niño Fernando de dos o tres años, haciendo un« show travesti » en la ventana de la casa, vestido con ropas rojas de la madre («zapatos rojos de tacón alto en punta, medias caladas, falda rojo encendido, cinturón rojo, cartera roja, guantes rojos, collar rojo de perlas, sombrero de velo rojo »). Ante una multitud heterogénea ( los vendedores ambulantes que venden naranjas, los choferes que manejan camiones, las beatas que vuelven de misa, las criadas que van a la tienda, los policías que agarran ladrones, todos en la calle me miraban incrédulos, pasmados de estupor »), Fernando se levanta la falda para orinar despreocupado por entre las rejas hacia el público (31-32). funcionan como posibles recuerdos encubridores, sino que son fundadores : a partir de ese texto, la obra, la palabra, la figura de Vallejo, como lo hace la quebrada La Loca, van a lanzarse barranca abajo sobre Medellín, sobre Colombia, en un tumulto discursivo hecho de exabruptos, de radicalidad, de insultos, pero también de una apasionada nostalgia por una sociedad y una lengua del pasado. Aparentemente inmune al qué dirán, el escritor, como el niño travestido orinando en la ventana, va a poner en escena provocaciones, exhibiciones, transgresiones. A partir de la onomatopeya, de la oralidad, de la hipérbole, de la furia, de la denuncia y de la melancolía, un tono, un estilo, una posición se definen, elementos que enmarcan la obra posterior de Vallejo.

Es decir que estas escenas, supuestamente situadas en el pasado, no corroboran ni completan una figura de autor, sino que la inventan; no son justificaciones legendarias de un tipo de escritura, sino que la crean; no explican un devenir, sino que se abalanzan, como la Loca por la cañada y el niño Fernando por el patio, hacia el espacio público con una palabra furiosa y profética. La escena del pasado, el recuerdo de infancia, son, en realidad, un programa para el porvenir. La obra por escribirse (incluyendo en ella, claro está, al personaje público Vallejo y su peculiar posición discursiva), no hará sino prolongar y repetir estas escenas primitivas. El pasado, el origen, la infancia, no sólo interactúan con un ahora de la escritura, sino que son el inicio dinámico de una obra por venir. En ese sentido, no es sorprendente que al final de la serie, en el último párrafo de Entre fantasmas (1993), se citen exactamente las primeras líneas de Los ríos azules y en

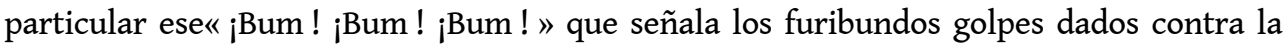
puerta cerrada del mundo y anuncian la aguda palabra del futuro (2005: 711). Vallejo, desde el improperio, la polémica, la diatriba, desde una interlocución constante e inestable, desde un vitalismo discursivo torrencial, desde un ritmo y una constante invención estilística, desde la subjetividad sufriente y la denuncia, va a irrumpir en elun 
mundo literario colombiano que reaccionará con perplejidad ante este niño iracundo, transgresivo e indomable.

Estas últimas afirmaciones remiten a un nivel evocado en todos los ejemplos anteriores : la cuestión de la figura de autor (o autora). Si Vallejo se inscribe en una transgresión polémica, en la cual el discurso público del escritor y el discurso literario de sus obras tiende a confundirse, en Lange y Felisberto, ese tono ligero, infantil y soñador por un lado, infantil y femenino por el otro, esbozan también una figura tenue de escritor/ escritora, que va a instalarse tanto en lo menor como en lo marginal. En todo caso, los tres ejemplos muestran cómo se puede volver a la infancia con otras estrategias que las de la explicación mágica o la automitificación. En estos casos, el pasado es un terreno de exploración narrativa, se privilegia la búsqueda de un tipo de escritura y los procesos problemáticos de la representación a la narración ordenada y explicativa. La dinámica temporal que caracteriza estos textos es por lo tanto radicalmente diferente a los ejemplos canónicos: lo narrado, aunque potente, eficaz en su capacidad de evocar el universo infantil -que en este caso resulta más verosímil que los de Neruda, Arenas o García Márquez-, no es un retorno al origen, sino una proyección hacia el futuro. El pasado, la infancia, sus perplejidades, sus incoherencias, su extrañeza, no son la evocación de lo perdido sino la construcción de un mundo literario posible. Infancias futuras por lo tanto ; la autobiografía es, aquí, una fundación.

Dime cómo recuerdas tu infancia y te diré qué escritor eres, podría afirmarse en conclusión. 0 recordar que escribir la infancia es escribir la memoria, es decir una visión de lo que fue desde la subjetividad del presente, una escenificación que busca, de una manera $\mathrm{u}$ otra, darle coherencia y volver tanto inteligible como utilizable lo caótico del pasado. La memoria no reproduce, nos dicen las neurociencias y la psicología cognitiva, sino produce, en procesos diferentes, inestables e interpretativos, escenas a partir de las percepciones recibidas. Por ende, la memoria no reside en convocar en la conciencia circunstancias siempre idénticas tal cual sucedieron, sino que funciona como una construcción a partir de los estímulos de una situación presente y en respuesta a ellos. La memoria, situada más allá de la verdad o de la falsedad, es el cimiento de la posibilidad de acción en el mundo actual.

En este sentido, más que metaforizarla con la imagen tópica de la inscripción en la roca, habría que decir, como lo hace Gerald Edelman, que la memoria funciona como el « fundirse y volverse a congelar de un glaciar. Es un proceso que se reitera una y otra vez, creando en cada una de sus ocurrencias un producto distinto, aun cuando se componga con materiales similares " : año tras año el glaciar se derrite en el olvido y se congela cuando se recuerda. Cada episodio de rememoración se lleva a cabo con los mismos materiales, herederos de la primera evocación, pero que, cada año, adquieren una forma levemente distinta. Por lo tanto, a fuerza de congelarse y fundirse, de rememorar y olvidar, sólo se accede a la última capa, resultado de un largo proceso (Feierstein, 2002 : 56-57). En este sentido, los relatos de infancia pueden ser una ficción postrera antes de la muerte, como las de Neruda, Arenas y García Márquez, una ficción que sea un modo de consolarse suponiendo que, desde lo alto de una cordillera de libros, personajes, peripecias, fabulaciones, proyecciones e imaginario, construida a lo largo de tantos inviernos y de toda una obra, suponiendo entonces que desde ese punto panorámico y casi póstumo, se va a encontrar, por fin, un sentido definitivo en la forma diferente que toma esta vez lo ya narrado o ya cantado. $O$ al contrario, la infancia puede ser vista como una cantera de materiales con los cuales construir otra cosa -es lo que hacen Felisberto, 
Lange y Vallejo-, es decir transformar cada vez lo mismo en algo nuevo, aprovechando ese momento frágil del otoño para manipular un hielo todavía dúctil y así esbozar formas inéditas (túneles, catedrales, valles, laberintos, montañas, corrientes y arabescos), todas inestables, todas efímeras, pero potentes y fundadores, bellísimas cuando nosotros las leemos bajo la espléndida luz de un sol de primavera.

\section{BIBLIOGRAFÍA}

Agamben, Giorgio. Enfance et histoire : destruction de l'expérience et origine de l'histoire. París : Payot, 1989

Arenas, Reinaldo. Antes que anochezca (1992). Madrid : Tusquets, 1994.

Arent, Hannah. De la historia a la acción. Paidós : Barcelona, 1995, p. 75Benjamin, Walter. "Le Narrateur", Ecrits français, París : Folio, 1991.

Brauer, Daniel. "La interpretación del recuerdo. 'Construcciones' de la memoria según Freud y su función en la narración del pasado", en Omar Acha y Mauro Vallejo (eds), Inconsciente e historia después de Freud. Cruces entre filosofía, psicoanálisis e historiografía, Buenos Aires : Prometeo, 2010.

Feierstein, Daniel. Memorias y representaciones. Sobre la elaboración del genocidio, Buenos Aires : Fondo de Cultura Económica.

García Márquez, Gabriel. Vivir para contarla. Madrid : Mondadori, 2002.

Gefen, Alexandre. "C'est avec l'histoire que les enfants jouent", Alain Schaffner (ed.). L'Ere du récit d'enfance. Arras : Artois Presses Université, 2005.

Green, André. Le temps éclaté. Paris : Minuit, 2000.

Hernández, Felisberto. Obras completas (3 tomos). México : Siglo XXI, 1996

Kermode, Franz. El sentido de un final. Barcelona : Gedisa, 2000.

Lange, Norah. Obras completas (2 tomos). Rosario : Beatriz Viterbo, 2005

Lejeune, Philippe. Les brouillons de soi. Paris : Seuil, 2003, p. 36.

Neruda, Pablo. Confieso que he vivido. Memorias. Barcelona : Seix Barral, 1974.

Neruda, Pablo. Canto general. Barcelona : Seix Barral, 1983.

Piaget, Jean. La représentation du monde chez l'enfant. París : PUF, 1999.

Robert, Marthe. Roman des origines, origines du roman. París : Grasset, 1972.

Vallejo, Fernando. Los días azules (1985) en El río del tiempo. Bogotá: Alfaguara, 2002.

\section{NOTAS}

1. Ver, al respecto y por ejemplo, "La illusion biographique" de Pierre Bourdieu en Raisons pratiques. Sur la théorie de l'action, París : Seuil, 1994, p. 81-90. 
2. Por ejemplo, leemos al principio del libro: «Hasta la adolescencia, la memoria tiene más interés en el futuro que en el pasado, así que mis recuerdos del pueblo no estaban todavía idealizados por la nostalgia. Lo recordaba como era : un lugar bueno para vivir, donde se conocía todo el mundo, a la orilla de un río de aguas diáfanas que se precipitaban por un lecho de piedras pulidas, blancas y enormes como huevos prehistóricos » (p. 11).

3. Felisberto Hernández, Obras completas (3 tomos), México : Siglo XXI, 1996 (en el tomo 1 figura Por los tiempos de Clemente Colling y en el tomo 2 El caballo perdido).

4. En una tesis doctoral próximamente defendida en la Université Paris 8. Sobre la percepción y la función de la imagen en Felisberto Hernández, un artículo suyo es esclarecedor y sintético : Laura Corona Martínez, "La narración digresiva : las imágenes en Felisberto Hernández. Una revisión de los procedimientos", Cahiers de LI.RI.CO [en línea], 5|2010. URL: http:// lirico.revues.org/405

5. Norah Lange, Obras completas (2 tomos), Rosario: Beatriz Viterbo, 2005. En el tomo 1 figura Cuadernos de infancia y en el tomo 2 Antes que mueran y Personas en la sala. Sobre la función fundadora del libro, ver Sylvia Molloy, "Juego de recortes : Cuadernos de infancia de Norah Lange", en Acto de presencia. La escritura autobiográfica en Hispanoamérica, México : FCE, 1996, p. 169-184.

\section{RESÚMENES}

El artículo lleva a cabo un balance de ciertas características generales de los relatos de infancia de los escritores. En particular, se pone de relieve la función de laboratorio estético que pueden tener esos episodios autobiográficos. En una segunda parte, se contraponen dos tipos de infancias: las que se escriben desde la vejez, bajo la tonalidad del testamento, y las que, al contrario, funcionan como la fundación de un proyecto y una estética. Pablo Neruda, Reinaldo Arenas, Gabriel García Márquez, Felisberto Hernández, Norah Lange y Fernando Vallejo son citados como ejemplos de estas dos posibilidades.

L'article réalise un bilan de certaines caractéristiques générales des récits d'enfance des écrivains. En particulier, on y met en relief la fonction de laboratoire esthétique que ces épisodes autobiographiques peuvent avoir. Dans une deuxième partie, on juxtapose deux types d'enfance : celles qui sont écrites dans la vieillesse, sur la ton du testament, et celles qui, au contraire, fonctionnent comme la fondation d'un projet et d'une esthétique. Pablo Neruda, Reinaldo Arenas, Gabriel García Márquez, Felisberto Hernández, Norah Lange et Fernando Vallejo sont cités pour illustrer ces deux possibilités.

The article makes an overview of some general characteristics of author's childhood stories. In particular, it highlights the function that these autobiographical episodes may have as an aesthetic laboratory. In the second part, it juxtaposes two types of childhood: those that are written in old age, with the tone of a testament, and those which, on the contrary, function as the foundation of a project and an aesthetic. Pablo Neruda, Reinaldo Arenas, Gabriel García Márquez, Felisberto Hernández, Norah Lange and Fernando Vallejo are cited to illustrate these two possibilities. 
ÍNDICE

Palabras claves: infancias, autobiografía, figura de autor, memoria, orígenes

Keywords: childhoods, autobiography, memory, origin, author figure

Mots-clés: enfances, autobiographie, figure d'auteur, mémoire, origines

\section{AUTOR}

JULIO PREMAT

Université Paris 8 Vincennes - Saint-Denis 